Int. J. Dev. Biol. 61: 591-600 (2017)

doi: $10.1387 / \mathrm{ijdb} .170118 \mathrm{ky}$

\title{
Early development of amphioxus links evolutionary events with vertebrates
}

\author{
KINYA YASUI* \\ Department of Anthropology, National Museum of Nature and Science, Amakubo, Tsukuba, Ibaraki, Japan
}

\begin{abstract}
Comparison of early development is a powerful approach to understand how spherical embryos set up the basis for body patterning. Localization of the germ plasm likely couples with the site of gastrulation in many animals including cnidarians. A center of single or complex Wnt signaling pathway(s) is also co-localized with germ plasm and plays a role primarily in antero-posterior patterning in most animals. In addition, a Nodal signaling center appears in deuterostomes perpendicular to Wnt signaling and governs dorso-ventral patterning. Wnt and Nodal signaling pathways function as orthogonal coordinates to pattern embryos in three-dimensions. Amphioxus early embryos establish similar coordinates, but the location of Wnt signaling along the equator might modify the function of the Nodal signaling center to specify the chordate basic body pattern inverting dorso-ventral polarity, which is thought to have occurred during the evolution of deuterostomes. Surprising similarities in early developmental processes found in cnidarians and deuterostomes, and divergences of cnidarians-bilaterians, deuterostomes-protostomes, and ambulacrarians-chordates occurred one after another possibly within a geologically short period may link molecular mechanisms that gave rise to bilaterians, deuterostomes, and chordates.
\end{abstract}

KEY WORDS: lancelet, cnidarian, signaling center, germ plasm, body patterning

\section{Introduction}

Cephalochordate amphioxus (or lancelets) have long attracted many biologists who marvel in animal evolution, at least since the time of Russian embryologistA. O. Kowalevsky, who documented for the first time common developmental features shared by chordate embryos (Kowalevsky, 1867, 1871). When developmental biology and genetics began to be integrated in the 1980s via the introduction of molecular approaches, amphioxus was thus soon added to the list of research targets (Holland et al., 1992). However, owing to the lack of an adequate background of molecular studies unlike as in fruit flies, mice, sea urchins, frogs, zebrafish, and especially ascidians, the contribution of amphioxus studies to evolutionary developmental biology has been limited unfortunately.

Among the extant animals, amphioxus displays development and anatomy most similar to those of vertebrates. Seemingly for this reason, most studies on amphioxus since the 1990s have tried to find out how amphioxus development is homologous with that of vertebrates from the viewpoint of molecules. However, it has long been known that amphioxus possesses its own specific features, for example left-right asymmetrical development. Furthermore, fossil evidence and recent phylogenetic analyses suggest a deep split of the amphioxus lineage from the other chordates, coeval with the diversification of phyla during the Cambrian Explosion (Shu et al., 1999; Erwin et al., 2011; Yue et al., 2015). Phylogenetic analyses also suggest that many of the major divergences such as cnidarians-bilaterians, superphyla including Deuterostomia and Protostomia within bilaterians, ambulacrarians-chordates, and cephalochordates-olfactoreans (tunicates + vertebrates) occurred soon before or after the Precambrian/Cambrian boundary dated to $542 \mathrm{Ma}$ (Antcliffe, 2012; Cavalier-Smith, 2017). The phylogenetic position of amphioxus thus implicates the possibility that extant amphioxus still retains unique characters that can help unravel the origin of chordates, which might have been lost in the olfactorean lineage.

Molecular developmental studies are continuously providing new approaches to help understand a large set of data obtained from a variety of animals from sponges to vertebrates. These studies, especially on cnidarians and bilaterians, emphasize common mechanisms underlying the initial organization in eggs and early embryos to coordinate the apico-blastoporal, dorso-ventral (or directive), and left-right body axes, as well as their interactions.

Abbreviations used in this paper: BMP, bone morphogenetic protein.

\footnotetext{
*Address correspondence to: Kinya Yasui. Department of Anthropology, National Museum of Nature and Science, Amakubo, Tsukuba, Ibaraki, Japan e-mail: furaha13@icloud.com - (iD http://orcid.org/0000-0002-6704-883X
} 

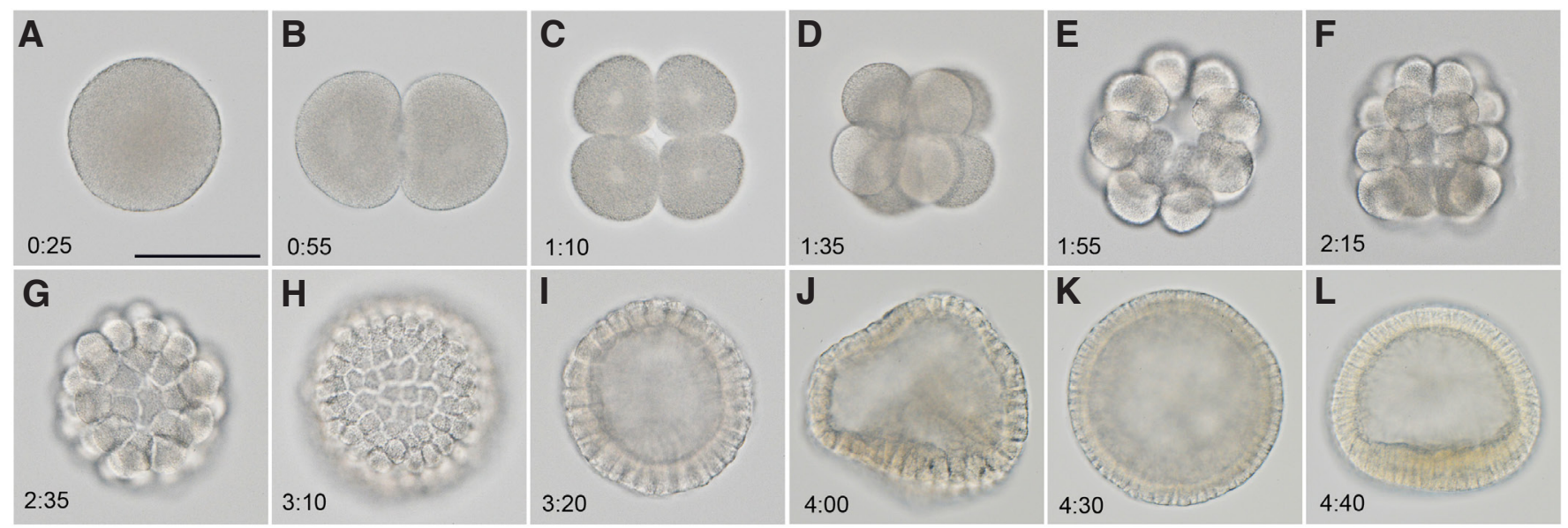

Fig. 1. Embryonic development of amphioxus Branchiostoma japonicum up to initial gastrula. After developing into 128-cell blastula, cell division becomes unsynchronized (J). (A) 1-cell, (B) 2-cell, (C) 4-cell, (D) 8-cell, (E) 16-cell, (F) 32-cell, (G) 64-cell, (H) 128-cell, (I) 128-cell smooth surface blastula, (J) deformed blastula, (K) spherical late blastula, and (L) initial gastrula. Times post fertilization are in development at $25^{\circ} \mathrm{C}$. Scale bar 100 um.

Viewing these common mechanisms, a common origin of ciliate larvae (Marlow et al., 2014), a basic pattern of bilaterian nervous system (Arendt et al., 2016), and the origin of chordate body pattern (Morov et al., 2016) have all been proposed. In this review, I integrate advances in recent understandings of early embryonic patterning in cnidarians and deuterostomes that display easily common and comparable early embryonic stages, and discuss the potential contribution of amphioxus developmental studies to the broad understanding of bilaterian evolution leading to chordates.

\section{Amphioxus has an advantage in comparative studies of early development}

As a member of the chordates, one advantage of amphioxus in comparative studies is that despite its body being reminiscent of vertebrate bodies, amphioxus develops from a spherical coeloblastula that is comparable to outgroup ambulacrarian blastulae (Giudice, 1986; Röttinger et al., 2015) and even remotely to some cnidarian blastulae (Lee et al., 2007). A fertilized egg of amphioxus starts cleaving at $40 \mathrm{~min}$ after sperm entry and then synchronously with 20 min intervals, producing almost equal-sized blastomeres (vegetal blastomeres are slightly larger than animal ones, in general) at $24^{\circ} \mathrm{C}$ in the case of Branchiostoma japonicum (Sino-Japanese populations formerly assigned to B. belcheri) (Fig. 1). Synchronized cleavage up to the 128-cell stage produces a spherical single-layered blastula. Then, likely after two rounds of unsynchronized cleavages that largely deform the blastula shape to become similar to that of an anthozoan Nematostella blastula (Fritzenwanker et al., 2007), the vegetal side of the recovered spherical blastula becomes flattened to start gastrulation (Fig. 1JL). Although cnidarians are phylogenetically distinct from bilaterian chordates, a considerable number of cnidarian species show cleavage patterns similar to chordate radial and equal cleavage, which might suggest that radial cleavage is an ancestral character. The cleavage of amphioxus egg is commonly cited in textbooks as a typical radial and equal cleavage. Passing through this cleavage and gastrulation, the antero-posterior axis of the embryo is kept to coincide with the egg animal-vegetal axis as in cnidarians and ambulacrarians (Yu et al., 2003), but is never rotated unlike as ascidians and vertebrates do (Koide et al., 2002; Lee et al., 2006; Nishida, 2005).

Ambulacrarian sea urchins and hemichordate acorn worms show similar cleavage patterns to the amphioxus pattern and produce spherical blastulae, but their blastomeres are more unequal between meridian blastomeres than in amphioxus, particularly in the case of macromeres and micromeres in sea urchin embryos (Giudice, 1986; Röttinger and Lowe, 2012). In these animals, unsynchronized cleavage starts earlier than in amphioxus embryos. These differences in cleavage are apparently related to the selective inheritance of specific maternal molecules and cytoplasm into blastomeres. At the blastula stage, amphioxus and ambulacrarians attain mutually comparable spherical blastulae comprising almost equal-sized blastomeres, which enables the understanding of very basic spatial patterning of mRNAs that regulate zygotic genes for initializing body patterning under common coordinates. Their coeloblastulae also enable comparison with anthozoan development. Ascidians and vertebrates are derived in this aspect, and thus it is difficult to episodically compare their early development to that of remotely related animals.

\section{Germ plasm and localization of maternal mRNAs}

Although it is still controversial which is ancestral in germ line segregation in animals between preformation and epigenesis (Extavour and Akam, 2003; Leclère et al., 2012), many animals produce molecular milieu(s) called the germ plasm or "nuage" in oocytes to segregate germ cells from somatic cells. The germ plasm is usually formed near the nuclear membrane in growing oocytes and comprises mitochondria, cytoskeletons, ERs, proteins and RNA/protein complexes called RNPs (Kloc et al., 2014). The centrosome is reported to act as a seed for the aggregation of the germ plasm (Kloc et al., 2004). Maternal mRNAs and sometimes also their encoding proteins in the germ plasm represented by vasa, nanos, piwi, p/10, and pumilio regulate zygotic genes expression in germ line progenitors (King et al., 2005; Juliano et al., 2006; Cuykendall and Houston; 2010; Voronina et al., 2011). The germ plasm or a subcellular structure derived from the nuage, however, also contains mRNAs responsible for gastrulation in many animals 
and for endoderm and/or dorsal specification in cnidarians and deuterostomes such as those encoding proteins involved in Wnt signaling, Nodal, and T-box proteins (Zhang et al., 1998; Tao et al., 2005; Amiel and Houliston, 2009; Cuykendall and Houston, 2010; Gilligan, 2011). In anamniote vertebrates such as zebrafish and Xenopus, the nuage is formed and enlarged on the vegetal side of perinucleus as a Balbiani body and is translocated to the vegetal pole during oogenesis (Kloc and Etkin, 2005; Kosaka et al., 2007).

In cnidarians, the sea anemone Nematostella does not show unambiguous aggregation of the germ plasm in oocytes, but mediated by an animally located germinal vesicle (nucleus in oocyte) with unknown mechanisms, transcripts from duplicated vasa and nanosgenes are localized on the animal side (Extavour et al., 2005) (Fig. 2). Through the gastrulation that occurs at the animal pole, vasa and nanos mRNAs are then distributed around the blastopore and in the newly forming archenteron. In the hydrozoan Clytia, perinuclear aggregates of the germ plasm in growing oocytes have been detected by in situ hybridization with germ plasm specific piwi, nanos, vasa, and p/10 probes (Leclère et al., 2012). These mRNAs in mature oocytes surround the female pronucleus at the animal pole like Nematostella oocytes and are inherited by an i-cell population around the future blastopore during cleavage. The i-cell population finally distributes into the entodermal (endodermal) inner layer, comparable to as what occurs in the case of Nematostella (Leclère et al., 2012). As the hydrozoan i-cell population is made up of a kind of stem cell that can differentiate both to germ cells and various types of somatic cells through the adult life (Watanabe et al., 2009), the behavior of the Clitya germ plasm is comparable to that of other preformation bilaterians. In association with the germ line mRNAs, mRNAs/proteins involved in Wnt/ $\beta$-Catenin signaling (Plickert et al., 2006; Amiel and Houliston, 2009) and Strabismus that initiates Wnt/PCP signaling at the initial gastrulation (Kumburegama et al., 2011) are localized at the animal cortex. As a result of their localization of the maternal factors, cnidarian embryos start gastrulation at the animal pole (Lee et al., 2007; Martindale and Hejnol, 2009). Furthermore, comparable to the vertebrate dorsal organizer as the Spemann's organizer in amphibians and its equivalents, the blastopore margin on the animal side of Nematostella gastrulae can induce a secondary embryonic axis when it is grafted to another embryo (Kraus et al., 2007, 2015).

Amphioxus oocyte dynamics including the nuage and the localization of maternal factors are still poorly characterized, but some maternal mRNAs in eggs have been reported. Some germ line marker mRNAs such as vasa, nanos, piwi1, pl10, bruno2, and $t d r d$ (tudor-domain containing) are localized near the vegetal pole, and others such as pumilio, mago-nashi, and mex 3 are near the animal poles with some ubiquitously distributed mRNAs (Wu et al., 2011; Zhang et al., 2013; Yue et al., 2015; Dailey et al., 2016). Seemingly corresponding to these bipolar distributions of the germ line markers, mRNAs related to Wnt/ $\beta$-Catenin signaling are not localized to the vegetal side, from which gastrulation starts (Qian et al., 2013; Wang et al., 2016). Although wnt1, -6, -9, -11 mRNAs are reported to be expressed maternally, their expression is too weak to detect their distribution in eggs (Qian et al., 2013). These data may explain the ubiquitous nuclear accumulation of $\beta$-Catenin in cleaving embryos in amphioxus (Yasui et al., 2002; Holland et al., 2005). Interestingly, however, two mRNAs, tcf and $d s h$ (dishevelled), that are involved in $\mathrm{Wnt} / \beta$-Catenin signaling show localization on the animal side contrary to as in sea urchins and vertebrates (Lin et al., 2006; Wang et al., 2016).

In sea urchins, although the Balbiani body was recently reported in young oocytes, their later behavior during oogenesis is different from anamniote vertebrates and they are dispersed into the cortical region (Yakovlev, 2016) (Fig. 2). Despite the fact that sea urchin eggs do not translocate the perinuclear Balbiani body to the vegetal pole, small micromeres that are formed by the fifth cell division at the vegetal pole display features of typical germ cell precursors expressing vasa and nanosgenes (Yajima nad Wessel, 2012). Furthermore, a protein involved in Wnt/ $\beta$-Catenin signaling, Dsh, is localized at the vegetal pole as in Xenopus (Peng and Wikramanayake, 2013) and the earliest Wnt/ $\beta$-Catenin signaling is activated in the vegetal hemisphere, opposite to as in cnidarian embryos (Weitzel et al., 2004; Wikramanayake et al., 2004).

A Tgf $\beta$ family member, Nodal is also an important molecule in the basic body patterning in many animals as will be mentioned below. Maternal squint (= nodal) mRNA in zebrafish (Gore et al., 2005) and nodalmRNA in amphioxus (Morov et al., 2016) are critical for dorsal specification. In sea urchin and Xenopus embryos, although nodal gene is expressed zygotically, it is regulated by other Tgf $\beta$ members, Panda (Haillot et al., 2015) and Vg1 (Birsoy et al., 2006), respectively, both of which are expressed maternally. In vertebrates, some mRNAs encoding maternal Tgf $\beta$ proteins are
A
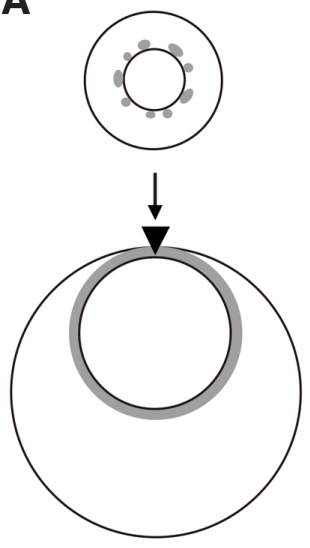

hydrozoan

(Clytia)
B
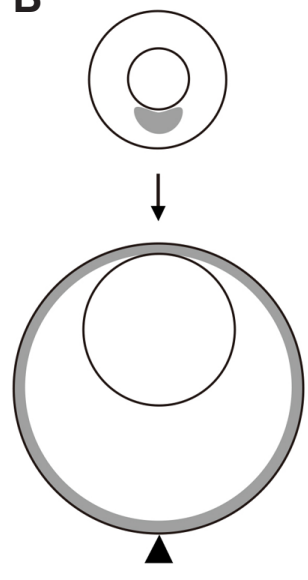

sea urchin
C
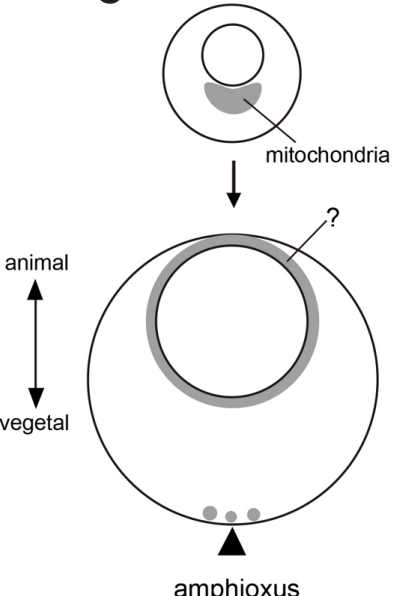

amphioxus
D
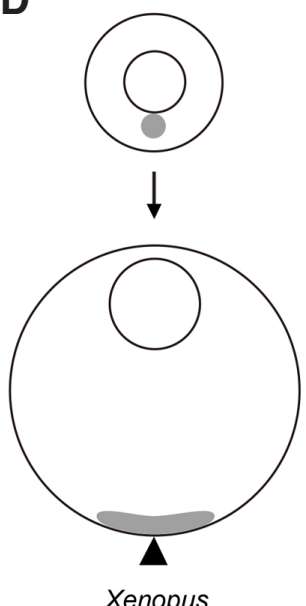

Xenopus
Fig. 2. Schematic drawing of germ plasm formation. Localization of germ plasm in young and mature oocytes is indicated as gray zones. Drawing for amphioxus oocytes is tentative. Arrowheads denote the site of gastrulation. (A) Cnidarian hydrozoan, (B) sea urchin, (C) amphioxus, and (D) Xenopus. 
co-localized with the germ plasm at the vegetal pole, whereas amphioxus nodal mRNA is ubiquitously distributed in unfertilized eggs and then accumulated in the animal hemisphere after sperm entry (Onai et al., 2010; Morov et al., 2016).

As reported for cnidarians and ascidians, although maternal mRNAs of germ line markers are aggregated in nuages or the germ plasm, the majority of these mRNAs are distributed evenly in the ooplasm, and germ line progenitors can be restored when the aggregate of the mRNAs is eliminated (Takamura et al., 2002; Shirae-Kurabayashi et al., 2006; Leclère et al., 2012). These observations make us cautious not to underestimate restoration mechanisms during development. Also, there are mRNAs important for initial body patterning, which have been observed to behave independently of the germ plasm (Pelegri, 2003). However, it is intriguing that the distribution pattern of maternal mRNAs in amphioxus eggs is somehow intermediate between cnidarian and sea urchin/vertebrate patterns. In amphioxus, a Balbiani bodylike structure is discernible as an aggregate of mitochondria in young oocytes (Figs. 2, 3), but bucky-ball and oskar genes that are involved in germ plasm formation in vertebrates or insects are absent (Marlow et al., 2008; Ewen-Campen et al., 2012). The mechanisms underlying perinuclear nuage aggregation in cnidarians and those producing the Balbiani body on the vegetal side in sea urchins and anamniote vertebrates are apparently key cues to understand the observed different strategies for the localization of maternal factors.

\section{Patterning of Wnt signaling and anti-Wnt components in blastulae}

At the blastula stage, animals that produce a single-layered spherical coeloblastula display impressive gene expression patterns in their blastulae (Fig. 4). They show apico-blastoporal axial patterning that corresponds to the vegetal-animal axis in cnidarians and to the animal-vegetal axis in bilaterians (Marlow et al., 2014). The inversion between cnidarians and bilaterians reflects the opposite localization of maternal factors mentioned above. The apical domain is characterized with transcription factors such as foxq2and six3/6, as well as with an Wnt receptor, $f z d 5 / 8$ (frizzled) in concentric expression, whereas the blastoporal domain is characterized with concentric expressions of wnt paralogues (Range et al., 2013; Cui et al., 2014). In the apical domain, $f z d 5 / 8$ is regarded as a mediator of Wnt that emanates from the opposite blastoporal side, and Wnt
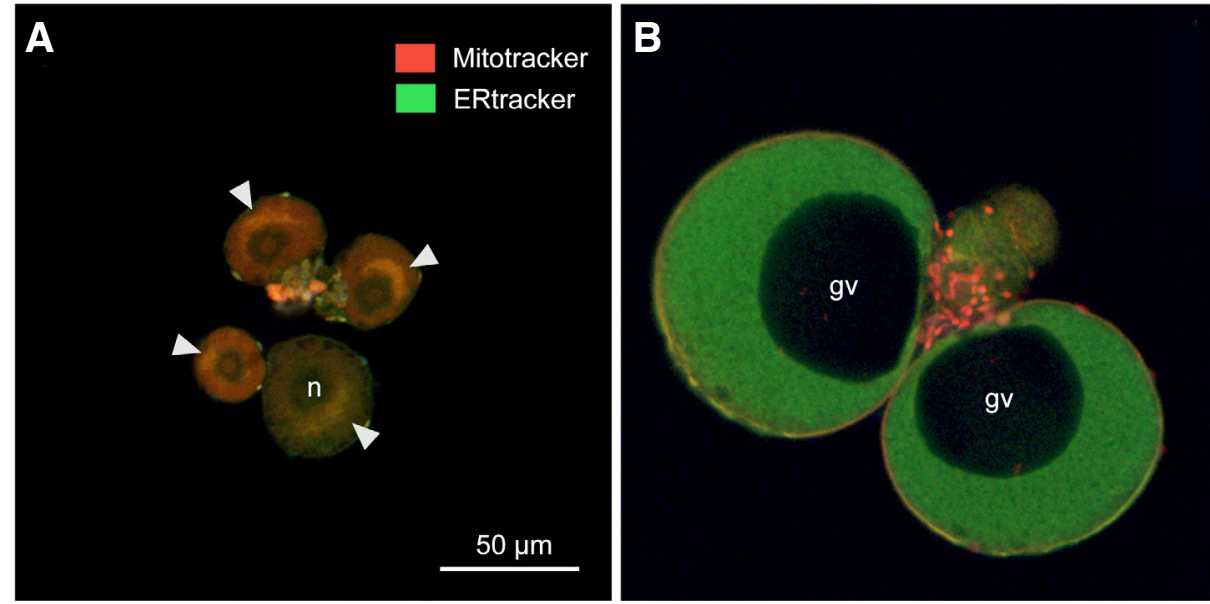

antagonists such as $d k k 1,3$ (dickkopf) and sfrp (secreted frizzledlike protein) are also expressed, depending on animal species (Lee et al., 2006; Range and Wei, 2016). Wnt signaling pathway(s) in the blastoporal domain regulates the size of the apical domain (Range et al., 2013), where cells extend long cilia to form an apical tuft and several types of sensory/neurosecretory cells differentiate to constitute an apical organ at larval stages (Marlow et al., 2014). Many protostome animals develop from rather specialized eggs. However, eutrochozoans that produce trochophore larvae also display a comparable gene expression pattern in the apical domain on the animal side, although Wnt signaling on the vegetal side is not well documented (Marlow et al., 2014).

In amphioxus blastulae, of the cardinal transcriptional factors in the apical domain, foxq2 and six 3 , only foxq2 is expressed broadly on the animal side towards the equatorial zone (Fig. 5). Initial foxq2 expression in almost the whole embryonic body and receding towards the animal hemisphere suggests an interaction with Wnt8 signaling. On the other hand, six $3 / 6$ expression is completely different from typical apical expression and occupies the dorsovegetal region and then gastrulating archenteron (Fig. 5). These expression patterns may be related to the apical expression of the Wnt antagonist $d k k 3$ (Yu et al., 2007) and ubiquitous expression of the Wnt receptor $f z d 5 / 8$ (Qian et al., 2013). On the blastoporal side, typical concentric expression of wnt paralogues does not appear, but instead the earliest expression detectable by in situ hybridization is circular expression of wnt8 along the equator at the late blastula stage (Yasui et al., 2001; Morov et al., 2016). Interestingly in amphioxus blastulae, Wnt antagonists $d k k 1 / 2 / 4$, sfzp3/4, and sfzp2-like are expressed on the blastoporal side (Yu et al., 2007). These gene expression profiles in amphioxus blastulae are atypical compared with those showing counter-gradients between Wnt signal and anti-Wnt components in other animals. Consistently, amphioxus embryos show no specific nuclear $\beta$-Catenin gradient but instead ubiquitous nuclear accumulation in blastulae (Yasui et al., 2002; Holland et al., 2005) and do not develop an apical tuft on the apical side.

In animals that develop to spherical coeloblastula and then gastrulate in the manner of invagination or its variants, the Wnt expression domain(s) at a pole defines the future blastopore margin. Beside Strabismus in Nematostella (Kumburegama et al., 2011), however, it is still unknown how and which Wnt signaling functions in gastrulation in each animal. In amphioxus embryos, only wnt8 expression has been confirmed in blastulae (Yasui et al., 2001; Yu et al., 2007; Morov et al., 2016). Its circular expression along the equator is soon followed by brachyury1 expression in the same domain, and the flattening of the vegetal plate expands to the equatorial region (Fig. 1L), suggesting that Wnt8 signaling plays a major role in amphioxus gastrulation. Many wnt paralogues are expressed maternally, but in wnt8 this is not the case (Qian et al., 2013).

Fig. 3. Mitochondrial distribution in amphioxus oocytes. (A) Mitochondrial aggregates are found on the opposite side of attaching site to germinal epithelium (vegetal side) in young oocytes (arrowheads). (B) There are no signals of Mitotracker in growing oocytes. Abbreviations: gv, germinal vesicle; $n$, nucleus. Scale bar, $50 \mu \mathrm{m}$. 
Fig. 4. Comparison of orthogonal Wnt and Nodal (Bmp) signalings. (A) Cnidarian, (B) sea urchin, and (C) amphioxus blastulae. Representative genes (or their products) and their interactions are indicated. Arrowheads denote the site of gastrulation. Apico-blastoporal inversion between cnidarians and sea urchins, and dorsoventral inversion between sea urchins and amphioxus are indicated.

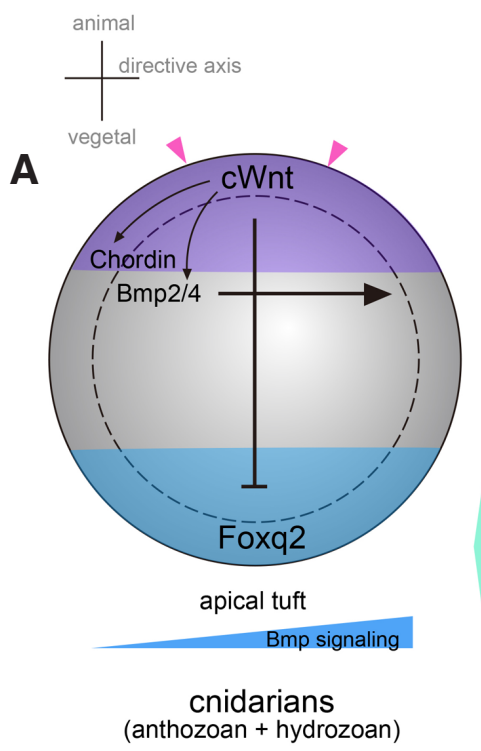

Because Wnt signaling on the blastoporal side likely functions as the initiator not only of gastrulation, but also of the apical specification to pattern embryonic apico-blastoporal axis, it is important to understand how the amphioxus system is derived from the typical pattern found in sea anemone and sea urchin embryos (Lee et al., 2007; Röttinger, 2012; Range et al., 2013; Watanabe et al., 2014).

\section{Chordin and Bmp in dorso-ventral specification}

The apico-blastoporal specification by Wnt signaling leads to antero-posterior body patterning, but this signaling itself does not give rise to dorso-ventral patterning. Bmp (Dpp; Decapentaplegic) and Chordin (Sog; Short gastrulation) play central roles in the dorso-ventral patterning in bilaterians (Sasai et al., 1995; Biehs et al., 1996). In the comparison between Xenopus and Drosophila, it

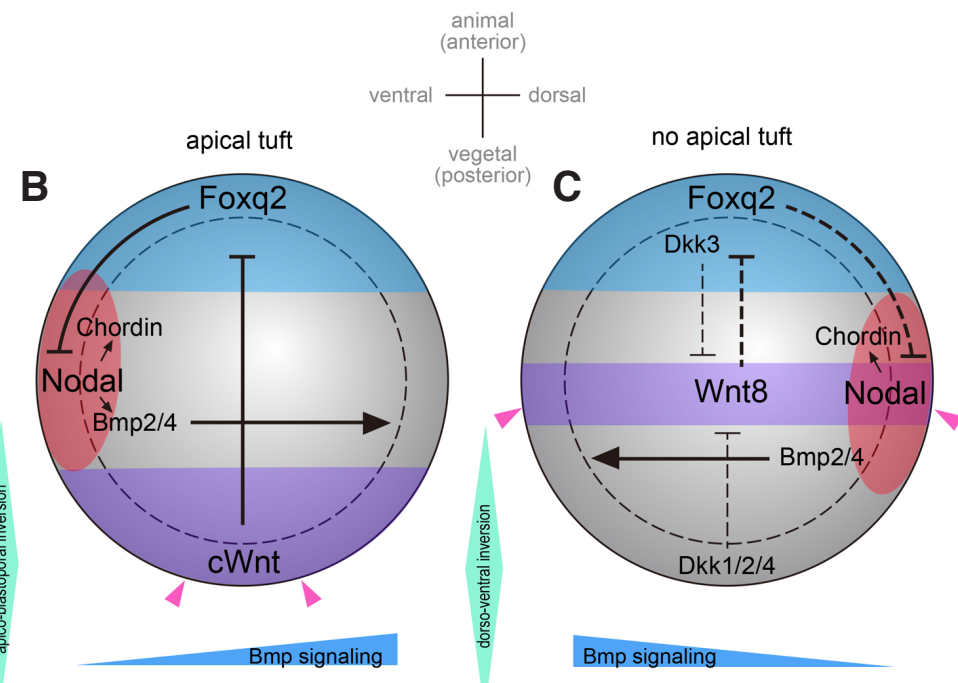

sea urchin amphioxus

was found out that chordin (sog) was expressed consistently side where the nerve cord develops and bmp4 (dpp) was expressed on the opposite side. These two genes thus have become a pair of good markers for dorso-ventral polarity (Lowe et al., 2006). In sea urchin embryos, however, both bmp2/4 and chordin are activated by Nodal signaling and co-expressed on the ventral (oral) side (Lapraz et al., 2009). In this situation, Bmp2/4 function is blocked by Chordin co-existing on the ventral side, but is accomplished on the dorsal (aboral) side by a Chordin-Bmp2/4 complex releasing Bmp2/4. Thus Bmp2/4 signaling on the dorsal side and Chordin blocking of this signaling on the ventral side correspond to protostome polarity.

Although sea anemone embryos do not differentiate dorso-ventral polarity, they display a secondary axis called the directive axis perpendicular to the primary animal-vegetal (blastoporal-apical) axis.
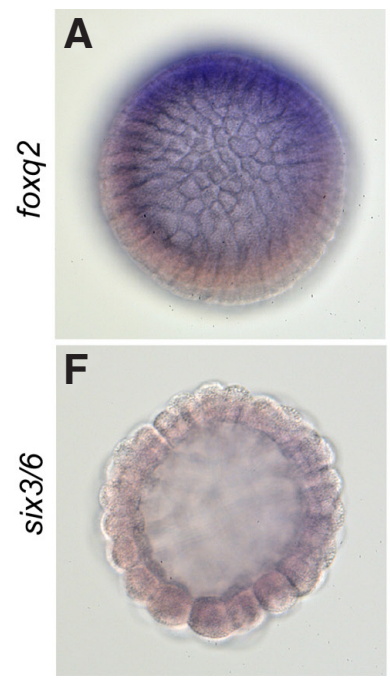
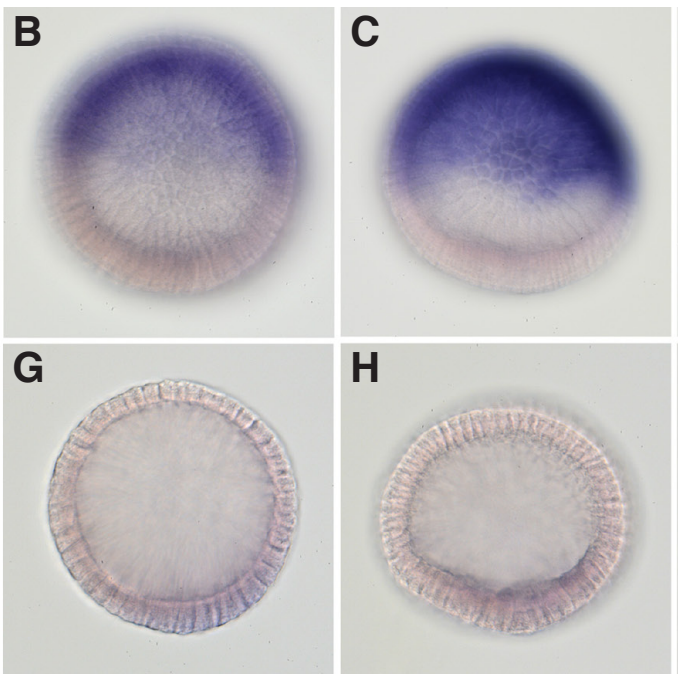
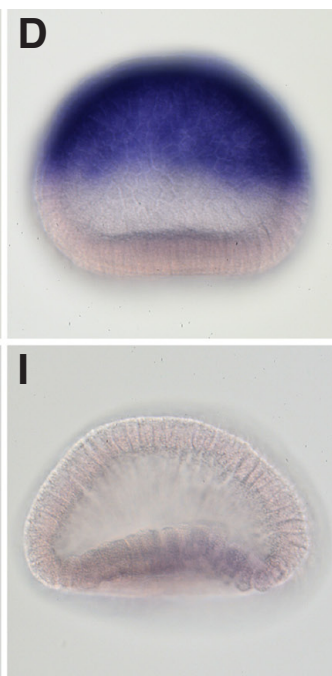

Fig. 5. Expression pattern of foxq2 and six3/6 at blastula and gastrula stages. (A-E) Whole-mount in situ hybridization probed with foxq2. (A) Early blastula, (B) late blastula, (C) onset of gastrulation, (D) gastrula with flattened vegetal plate, and (E) invaginating vegetal plate. (F-J) Whole-mount in situ hybridization probed with six3/6. (F) 128-cell stage, and (G-J) correspond to (B-E) in stage. Scale bar, $100 \mu \mathrm{m}$. 
Interestingly, sea anemone embryos first express both bmp2/4 and chordin genes around the blastopore margin and then translocate these expressions to one side of the future directive axis, where chordin is expressed in the outer layer (ectoderm) and bmp2/4 is in the inner layer (entoderm) (Rentzsch et al., 2006; Saina et al., 2009). The gradient of Bmp2/4 signaling, however, is highest on the opposite side as in sea urchin embryos, and GLWA positive neurons in the circular oral nervous system appear specifically on the weaker side (= chordin expression side) of Bmp2/4 signaling (Watanabe et al., 2014). The asymmetrical expression of bmp2/4 and chordin on the same side and the counter-gradient of Bmp2/4 signaling in sea urchin and sea anemone embryos are comparable to each other, and may be a retained ancestral feature (Lapraz et al., 2009). Furthermore, the asymmetrical development of GLWA positive neurons in the oral nervous system on the chordin side is reminiscent of the neuronal patterning in bilaterian trunk nervous systems (Watanabe et al., 2014), or more specifically of the central nervous system developing on the dorsal chordinside in chordates as Bmp2/4 signaling at the mid-ventral region in amphioxus embryos induces primary sensory neurons in the ectoderm (Lu et al., 2012).

Amphioxus dorso-ventral patterning is the same as that of vertebrates, and has been deduced from their expression patterns (Panopoulou et al., 1998; Morov et al., 2016), Chordin from the notochord most likely suppresses Bmp2/4 signaling in the dorsal ectoderm and functions to differentiate it into the neural plate as seen in vertebrates. However, both bmp2/4 and chordin are expressed in the archenteron on dorsal side and Bmp2/4 signaling is activated on the ventral side (Morov et al., 2016). This pattern is the same as in sea urchin embryos, but the direction is opposite along the dorso-ventral axis.

In sea anemone embryos, the activation of both bmp2/4 and chordin are dependent on Wnt/ $\beta$-Catenin signaling (Watanabe et al., 2014), and in sea urchin embryos both genes are regulated by Nodal signaling (Lapraz et al., 2009) that is indirectly regulated by Wnt/ $\beta$-Catenin signaling (Range et al., 2013). In hydra budding, Nodal signaling, which is utilized in the laterality of budding, is reported to be a downstream target of $\mathrm{Wnt} / \beta$-Catenin signaling (Watanabe et al., 2014). Amphioxus chordin is regulated as a downstream target gene by Nodal signaling as seen in sea urchin embryos (Yu et al., 2007; Morov et al., 2016), but the upstream regulator(s) of zygotic bmp2/4 in amphioxus is unknown, although blocking of Nodal signaling affects the bmp2/4 expression pattern, suggesting the involvement of Nodal signaling (Morov et al., 2016). These lines of circumstantial evidence suggest that both bmp2/4 and chordin expression on the same side and the counter-gradient of Bmp2/4 signaling are ancestral features that have been retained in cnidarians and deuterostome sea urchins and amphioxus (Fig.4).

\section{Nodal signaling at the initial embryonic patterning}

Nodal signaling was originally recognized as a regulator for mesoendodermal specification, as well as for antero-posterior and left-right axes specification before and during gastrulation in vertebrates (Schier and Shen, 2000). Of these functions, the role in left-right asymmetrical development has been highlighted (Saijoh et al., 2000; Duboc et al., 2005), and a similar Nodal signaling function was found even in a cnidarian hydra as a unit involving Pitx was reminiscent of its bilaterian counterpart, suggesting a deep origin of this signaling unit in animals (Watanabe et al., 2014).
In sea urchin embryos, another important role of Nodal signaling has been elucidated. A center of Nodal signaling is established in spherical blastulae perpendicular to the blastoporal-apical (vegetalanimal) Wnt/ $\beta$-Catenin signaling regime (Duboc et al., 2005; Yaguchi et al., 2008; Molina et al., 2013; Range et al., 2013). Accordingly, in sea urchin blastulae, orthogonal signaling systems, Wnt/ $\beta$-Catenin signaling along the antero-posterior axis, and Nodal signaling along the dorso-ventral axis regulate embryonic patterning. As the Nodal signaling center is established by zygotic Nodal-Lefty interaction (Duboc et al., 2005), it remains unknown how maternal factors regulate the formation of the center, although an asymmetrical redox gradient affected by mitochondria distribution in fertilized eggs (Coffman et al., 2001, 2004, 2009, 2014) or a maternal Tgf $\beta$ member Panda (Paracentrotus anti-nodal dorsal activity) (Haillot et al., 2015) have both been proposed as anti-initiators of nodal expression. This asymmetrical Nodal signaling activates bmp2/4 and chordin, as well as not and goosecoid, and in turn Goosecoid activates brachyury and foxa, producing the dorso-ventral patterning (Molina et al., 2013). The Nodal signaling domain itself becomes the oral (ventral) ectoderm in sea urchin embryos (Duboc et al., 2005). The ventral nodal expression in sea urchin embryos is also indirectly regulated by the perpendicular Wnt/ $\beta$-Catenin signaling as $\mathrm{Wnt} / \beta$-Catenin indirectly downregulates foxq2 on the animal side and Foxq2 suppresses Nodal autoregulation (Yaguchi et al., 2008; Range et al., 2013).

Amphioxus lefty has been known as one of the earliest genes expressed zygotically (Onai et al., 2010). Its expression pattern, reminiscent of sea urchin lefty, suggests that the amphioxus dorso-ventral patterning that involves Nodal signaling is similar to sea urchin mechanisms. Actually, nodal expression domain in amphioxus blastulae becomes matched with lefty domain across the equator and likely represents orthogonal signaling systems with some vegetal-animal signaling comparable to those in sea urchin embryos (Yaguchi et al., 2008; Morov et al., 2016). The asymmetrical Nodal signaling domain in the amphioxus spherical blastula regulates chordin, goosecoid, not-like, and brachyury 1 during gastrulation and then is located on one side of the margin of the blastopore, showing the same topology as the vertebrate dorsal organizer like the Spemann's organizer in amphibians (Morov et al., 2016).

Dorso-ventral inversion in bilaterians was proposed by Jeoffroy Saint-Hilaire in 1822. Recently, this idea has been supported as this inversion occurred during deuterostome evolution because a deuterostome hemichordate retains the same dorso-ventral polarity as that of protostomes (Lowe et al., 2006). The amphioxus Nodal expression domain is comparable to that in sea urchin blastulae, which further clarifies how and when the dorso-ventral inversion occurred in the bilaterian lineage. It is highly plausible that the dorso-ventral inversion occurred in the last common ancestor of chordates by converting the ancestral gene regulatory network for mouth specification to one for dorsal specification (Morov et al., 2016).

Nodal signaling in sea urchin embryos later displays a righthanded asymmetrical expression in prism larvae and induces pitx2 in the mesoderm precursor cell population at the tip of archenteron on the right side (Duboc and Lepage, 2008). In Branchiostoma japonicum embryos, nodal expression at the mid-dorsal blastopore margin likely induces pitx2 expression at the same region, which is shared with vertebrate embryos (Yasui et al., 2000). 
The mid-dorsal expression of nodal ceases but asymmetrical expression in the future anterior somitic region appears in early neurulae, with the left side stronger than the right side (Yu et al., 2002 for B. floridae and personal observation for B. japonicum). This asymmetrical expression soon activates pitx2 in the left first somite primordium (Yasui et al., 2000). Although in embryos of extant sea urchins and amphioxus asymmetrical pitx2 expression occurs on the opposite side, it is originally the same right side when considering the dorso-ventral inversion. Furthermore, in amphioxus the asymmetrical expression of the Nodal-Pitx gene regulatory network (GRN) in the left first somite induces a laterally located larval mouth under a similar mechanism as that for coelomic pore (hydropore) formation in ambulacrarians (Kaji et al., 2016). This diversion is necessary for amphioxus (and broadly for chordates) as amphioxus utilized the ancestral gene regulatory network for oral specification to specify new dorsal structures (Morov et al., 2016). Remarkably, in vertebrates and probably in olfactoreans, the Nodal-Pitx GRN derived from the mid-dorsal blastopore margin continuously functions at the anterior-most of neurulae and forms a median mouth by inducing the anterior pan-placode (Schlosser, 2005; Soukup et al., 2013). These observations suggest that the deuterostome Nodal-Pitx GRN shares a common origin with its hydra counterpart (Watanabe et al., 2014). The parallel Nodal-pitx2 regulation between sea urchin and amphioxus embryos is important in understanding how amphioxus larvae acquired left-right asymmetrical development.

\section{Amphioxus development not only looks forward, it also looks back}

As penta-radial echinoderm and bilateral amphioxus adults are largely different from each other, developmental studies on these two animals had, until recently, not been efficiently interactive. However, recent studies on the ventral Nodal signaling center in sea urchin embryos suggest a deep common origin with the vertebrate dorsal organizer (Molina et al., 2013; Lapraz et al., 2015). Supporting this, amphioxus embryos likely retain a developmental process to show how the ventral organizer can become the dorsal organizer (Morov et al., 2016). The linkage of the early development between chordates and ambulacrarians raises an important possibility; that the bilateral body of chordates does not need to have evolved from an animal that had acquired an adult bilateral body like enteropneust-type hemichordates.

Currently, it is commonly believed that the echinoderm ancestor was a bilateral animal in the morphological sense with a pentaradial body pattern in adults that was secondarily derived. Most extant echinoderms that perform metamorphosis are interpreted as manifesting a recapitulation of their evolutionary history of ancestral bilateral larvae and derived penta-radial adults. However, the earliest known echinoderm fossils, helicoplacoids, are already radially symmetrical animals (Dornbos and Bottjer, 2000), and morphologically bilateral echinoderm fossils appear later than these fossils (Zamora et al., 2012; Smith et al., 2013). Comparative studies on early development involving a wide range of animals but displaying a similar developmental strategy have shown surprisingly similar molecular strategies in their developmental processes. Cnidarian anthozoan and hydrozoan embryos show Wnt/ $\beta$-Catenin signaling gradients along the apico-blastoporal axis, and foxq2 and six3/6 are expressed on the apical (vegetal) side (Chevalier et al., 2006;
Sinigaglia et al., 2013; Marlow et al., 2014; Watanabe et al., 2014). High Wnt/ $\beta$-Catenin or Wnt/PCP signaling on the animal side induces gastrulation on this side, and the blastopore margin can induce a secondary embryonic axis like the vertebrate Spemann's organizer when grafted (Kraus et al., 2007, 2015). These molecular mechanisms are mostly applicable to sea urchin development, although the location where the mechanisms work is inverted in terms of the animal-vegetal axis, and include the observation that vegetal micromeres can induce secondary gastrulation when transplanted to the animal pole (Ransick and Davidson, 1993). The asymmetrical expression of Bmp2/4 and Chordin on the same side are also found both in cnidarians and deuterosotmes. In sea urchin blastulae, however, the Nodal expression domain appears on the future ventral side and establishes orthogonal coordinates with Wnt/ $\beta$-Catenin signals from the vegetal side (Yaguchi et al., 2008; Wei et al., 2012; Li et al., 2014). These molecular mechanisms in sea urchin embryos are in turn found in amphioxus embryos, although $\mathrm{Wnt} / \beta$-Catenin signaling along the animal-vegetal axis has apparently been modified, and this modification has likely given rise to the chordate body plan in this animal (Morov et al., 2016). Both differences found between cnidarians and sea urchins, and between sea urchins and amphioxus are likely related to the variation in localization of maternal factors mediated by nuages or a Balbiani body during oogenesis.

Amphioxus development thus may provide insights not only into the origin of vertebrates, but also into the origin of bilaterians. Although speculations on "urbilaterians" sometimes imagine a bilateral animal geared with full set of modern bilaterian features (De Robertis, 2008; Arendt et al., 2016), reminiscent of Owen's ideal archetype of the vertebrate skeleton (Owen, 1866), genomewide studies are now providing similarities rather than differences between cnidarians and bilaterians (Putnam et al., 2007; Dubuc et al., 2012; but see Boero et al., 2007; Schwaiger et al., 2014)), raising the possibility that bilaterian ancestors retained a radially symmetrical appearance. This is also supported by the fact that many bilaterians such as lophophorates, annelids and their close relatives, priapulids, and echinoderms that display radially symmetrical appearances in each superphylum clade branch off basally in the phylogenetic tree (Dunn et al., 2008). One remarkable difference between cnidarian and bilaterian clades is found instead in development as mentioned above; opposite localization of maternal factors in eggs along the animal-vegetal axis and the resultant inverted embryonic development. Gastrulation from the animal pole has also been reported for ctenophoran embryos (Freeman, 1977; Martindale and Hejnol, 2009) and both cnidarians and ctenophorans develop radially symmetrical bodies. The inversion of the site of gastrulation in terms of the animal vegetal axis is well known, as is the dorso-ventral inversion. However, molecular and subcellular mechanisms underlying the apico-blastoporal inversion and how they are related to segregate the bilaterian clade from radially symmetrical animal clades have not yet been elucidated. Given that early animal diversifications occurred rapidly around the Precambrian/Cambrian boundary (Rokas et al., 2005; Antcliffe, 2012; Cavalier-Smith, 2017), comparative study involving cnidarians, ambulacrarians, amphioxus, and protostome animals that may retain less-derived early developmental patterns, such as chaetognaths (Takada et al., 2002; Carré et al., 2002), phoronids (Pennerstorfer and Scholtz, 2012), and priapulids (Wannberg et al., 2008) may provide data for better understanding the bilaterian, 
deuterostome, and chordate origins. Cues for understanding these origins might couple with each other in oogenesis and early developmental processes.

\section{Acknowledgements}

I thank Z. Kozmik for his kind invitation to this special issue of IJDB and A. R. Morov and T. Kaji for their collaboration in lab research projects. Thanks are also due to Y. Henmi, A. Maenaka, and K. Shiohira for their support and help in maintaining the amphioxus laboratory colony and to J. D. Reimer for his English editing of this manuscript.

\section{References}

AMIEL A, HOULISTON E (2009). Three distinct RNA localization mechanisms contribute to oocyte polarity establishment in the cnidarian Clytia hemisphaerica. Dev Biol 327:191-203.

ANTCLIFFE JB (2012). Patterns in Palaeontology: The Cambrian explosion - Paradoxes and possible worlds. Palaeontol Online 2: 1-12.

ARENDT D, TOSCHES MA, MARLOW H (2016). From nerve net to nerve ring, nerve cord and brain - evolution of the nervous system. Nature Rev Neurosci 17: 61-72.

BIEHS B, FRANÇOIS V, BIER E (1996). The Drosophila short gastrulation gene prevents $D p p$ from autoactivating and suppressing neurogenesis in the neuroectoderm. Genes Dev 15: 2922-2934.

BIRSOY B, KOFRON M, SCHAIBLE K, WYLIE C, HEASMAN J (2006). Vg1 is an essential signaling molecule in Xenopus development. Development 133: 15-20.

BOERO F, SCHIERWATER B, PIRAINO S (2007). Cnidarian milestones in metazoan evolution Integr Comp Biol 47: 693-700.

CARRÉ D, DJEDIAT C, SARDET C (2002). Formation of a large Vasa-positive germ granule and its inheritance by germ cells in the enigmatic chaetognaths. Development 129: 661-670.

CAVALIER-SMITH T (2017) Origin of animal multicellularity: precursors, causes, consequences - the choanoflagellate/sponge transition, neurogenesis and the Cambrian explosion. Phil Trans R Soc B 372:20150476.

CHEVALIER S, MARTIN A, LECLÈRE L, AMIELA, HOULISTON E (2006). Polarised expression of FoxB and FoxQ2 genes during development of the hydrozoan Clytia hemisphaerica. Dev Genes Evol 216: 709-720.

COFFMAN JA, COLUCCIOA, PLANCHARTA, ROBERTSON AJ (2009). Oral-abora axis specification in the sea urchin embryo III. Role of mitochondrial redox signaling via $\mathrm{H}_{2} \mathrm{O}_{2}$. Dev Biol 330: 123-130.

COFFMAN JA, DAVIDSON EH (2001). Oral-aboral axis specification in the sea urchin embryo: I. Axis entrainment by respiratory asymmetry Dev Biol230: 18-28.

COFFMAN JA, MCCARTHY JJ, DICKEY-SIMS C, ROBERTSONAJ (2004). Oral-aboral axis specification in the sea urchin embryo: II. Mitochondrial distribution and redox state contribute to establishing polarity in Strongylocentrotus purpuratus. Dev Biol 273: 160-171.

COFFMAN JA, WESSELS A, DESCHIFFART C, AND RYDLIZKY K (2014). Oralaboral axis specification in the sea urchin embryo IV. Hypoxia radializes embryos by preventing the initial spatialization of nodal activity. Dev Biol 386: 302-307.

CUI M, SIRIWON N, LI E, DAVIDSON EH, PETER IS (2014). Specific functions of the Wnt signaling system in gene regulatory networks throughout the early sea urchin embryo. Proc Natl Acad Sci USA 111: E5029-E5038.

CUYKENDALL TN, DOUGLAS W. HOUSTON DW (2010). Identification of germ plasm-associated transcripts by microarray analysis of Xenopus vegetal cortex RNA. Dev Dyn 239:1838-1848.

DAILEY SC, FEBRERO PLANAS R, ROSSELL ESPIERA, GARCIA-FERNÀNDEZJ, SOMORJAI IML (2016). Asymmetric distribution of pl10 and bruno2, new members of a conserved core of early germline determinants in cephalochordates. Front Ecol Evol 3: 156.

DE ROBERTIS EM (2008). The molecular ancestry of segmentation mechanisms. Proc Nat Acad Sci USA 105: 16411-16412.: 10.1073/pnas.0808774105

DUBOC V, LEPAGE T (2008). A conserved role for the nodal signaling pathway in the establishment of dorso-ventral and left-right axes in deuterostomes. J Exp Zool B (Mol Dev Evol) 310: 41-53

DUBOC V, RÖTTINGER E, LAPRAZ F, BESNARDEAU L, LEPAGE T (2005). Left- right asymmetry in the sea urchin embryo is regulated by Nodal signaling on the right side. Dev Cell 9: 147-158.

DUBUC TQ, JOSEPH F. RYAN JF, SHINZATO C, SATOH N, MARTINDALE MQ (2012). Coral comparative genomics reveal expanded Hox cluster in the cnidarian-bilaterian ancestor. Integr Comp Biol 52: 835-841.

DUNN CW, HEJNOL A, MATUS DQ, PANG K, BROWNE WE, SMITH SA, SEAVER E, ROUSE GW, OBST M, EDGECOMBE GD, SØRENSEN MV, HADDOCK SHD, SCHMIDT-RHAESA A, OKUSU A, KRISTENSEN RM, WHEELER WC, MARTINDALE MQ, GIRIBET G (2008). Broad phylogenomic sampling improves resolution of the animal tree of life. Nature 452: 745-749.

ERIC RÖTTINGER E, DUBUC TQ, ALDINE R. AMIELAR, MARTINDALE MQ (2015) Nodal signaling is required for mesodermal and ventral but not for dorsal fates in the indirect developing hemichordate, Ptychodera flava. Biol Open 00: 1-13.

ERWIN DH, LAFLAMME M, TWEEDT SM, SPERLING EA, PISANI D, PETERSON KJ (2011). The Cambrian conundrum: Early divergence and later ecological success in the early history of animals. Science 334: 1091-1097.

EWEN-CAMPEN B, SROUJIJR, SCHWAGEREE, CASSANDRAG. EXTAVOUR CG (2012) oskarpredates the evolution of derm plasm in insects. Cell22, 2278-2283

EXTAVOUR CG, AKAM M (2003). Mechanisms of germ cell specification across the metazoans: epigenesis and preformation. Development 130: 5869-5884.

EXTAVOUR CG, PANG K, MATUS DQ, MARTINDALE MQ (2005). Vasa and nanos expression patterns in a sea anemone and the evolution of bilaterian germ cell specification mechanisms. Evol Dev 7: 201-215.

FREEMAN G (1977). The establishment of the oral-aboral axis in the ctenophore embryo. J Embryol Exp Morphol 42: 237-260.

FRITZENWANKER JH, GENIKHOVICH G, KRAUS Y, TECHNAU U (2007). Early development and axis specification in the sea anemone Nematostella vectensis. Dev Biol 310: 264-279.

GILLIGAN PC, KUMARI P, LIM S, CHEONG A, CHANG A, SAMPATH K (2011). Conservation defines functional motifs in the squint/nodal-related 1 RNA dorsal localization element. Nucleic Acids Res 39: 3340-3349.

GIUDICE G (2011). The Sea Urchin Embryo: A Developmental Biological System. Softcover. Reprint of the original 1st ed. 1986, Springer-Verlag, Verlin.

GORE AV, MAEGAWA S, CHEONG A, GILLIGAN PC, WEINBERG ES, SAMPATH $\mathrm{K}$ (2005). The zebrafish dorsal axis is apparent at the four-cell stage. Nature 438: 1030-1035.

HAILLOT E, MOLINA MD, LAPRAZ F, LEPAGE T (2015). The maternal Maverick GDF15-like TGF- $\beta$ ligand $P$ anda directs dorsal-ventral axis formation by restricting Nodal expression in the sea urchin embryo. PLoS Biol 13: e1002247.

HOLLAND LZ, PANFILIO KA, CHASTAIN R, SCHUBERT M, HOLLAND ND (2005) Nuclear $\beta$-Catenin promotes non-neural ectoderm and posterior cell fates in amphioxus embryos. Dev Dyn 233:1430-1443.

HOLLAND PWH, HOLLAND LZ, WILLIAMS NA. HOLLAND ND (1992). An amphioxus homeobox gene: sequence conservation, spatial expression during development and insights into vertebrate evolution. Development 116: 653-661.

JULIANO CE, VORONINA E, STACK C, ALDRICH M, CAMERON AR, WESSEL GM (2006). Germ line determinants are not localized early in sea urchin development but do accumulate in the small micromere lineage. Dev Biol 300: 406-415.

KAJI T, REIMER JD, MOROV AR, KURATANI S, YASUI K (2016). Amphioxus mouth after dorso-ventral inversion. Zool Lett 2: 2

KING ML, MESSITT TJ, MOWRY KL (2005). Putting RNAs in the right place at the right time: RNA localization in the frog oocyte. Biol Cell 97: 19-33.

KLOC M, BILINSKI S, DOUGHERTY MT, BREY EM, ETKIN LD (2004). Formation, architecture and polarity of female germline cyst in Xenopus. Dev Biol266, 43-61.

KLOC M, ETKIN LD (2005). RNA localization mechanisms in oocytes. J Cell Sci 118: $269-282$.

KLOC M, JEDRZEJOWSKA I, TWORZYDLO W, BILINSKI SM (2014). Balbiani body nuage and sponge bodies e The germ plasm pathway players. Arthropod Struct Dev 43: 341-348.

KOIDE T, UMESONO K, HASHIMOTO C (2002). When does the anterior endomesderm meet the anteriormost neuroectoderm during Xenopus gastrulation? Int $\mathrm{J}$ Dev Biol. 46: 777-783.

KOSAKAK, KAWAKAMI K, SAKAMOTOH, INOUE K(2007). Spatiotemporal localization of germ plasm RNAs during zebrafish oogenesis. Mech Dev 124: 279-289.

KOWALEVSKY AO (1867). Entwickelungsgeschichte des Amphioxus lanceolatus. 
Memoires de l'Academie Imperiale des Sciences de St.-Petersbourg VII 11: 1-17.

KOWALEVSKY AO (1871). Weitere Studien über die Entwicklung der einfachen Ascidien. Arch Mikrosk Anat 7:101-130.

KRAUS Y, AMAN A, TECHNAU U, GENIKHOVICH G (2015). Pre-bilaterian origin of the blastoporal axial organizer. Nature Comm 7: 11694.

KRAUS Y, FRITZENWANKER JH, GENIKHOVICH G, TECHNAU U (2007). The blastoporal organiser of a sea anemone. Curr Biol 17: R874-R876.

KUMBUREGAMAS, WIJESENAN, XUR, WIKRAMANAYAKEAH (2011). Strabismusmediated primary archenteron invagination is uncoupled from $\mathrm{Wnt} / \beta$-catenin dependent endoderm cell fate specification in Nematostella vectensis (Anthozoa, Cnidaria): Implications for the evolution of gastrulation. EvoDevo 2011, 2: 2. http:// www.evodevojournal.com/content/2/1/2.

LAPRAZ F, BESNARDEAU L, LEPAGE T (2009). Patterning of the dorsal-ventral axis in echinoderms: Insights into the evolution of the BMP-Chordin signaling network. PLOS Biol 7: e1000248.

LECLÈRE L, JAGER M, BARREAU C, CHANG P, LE GUYADER H, MANUEL M, HOULISTON E (2012). Maternally localized germ plasm mRNAs and germ cell/ stem cell formation in the cnidarian Clytia. Dev Biol 364: 236-248.

LEE PN, KUMBUREGAMAS, MARLOWHQ, MARTINDALE MQ, WIKRAMANAYAKE $\mathrm{AH}$ (2007). Asymmetric developmental potential along the animal-vegetal axis in the anthozoan cnidarian, Nematostella vectensis, is mediated by Dishevelled. Dev Biol 310: 169-186

LEE PN, PANG K, MATUS DQ, MARTINDALE MQ (2006). A WNT of things to come: Evolution of Wnt signaling and polarity in cnidarians. Sem CellDevBiol17:157-167.

LIE, CUI M, PETER IS, DAVIDSON EH (2014) Encoding regulatory state boundaries in the pregastrular oral ectoderm of the sea urchin embryo. Proc Natl Acad Sci USA 111: E906-E913.

LIN HC, HOLLAND LZ, HOLLAND ND (2006). Expression of the AmphiTcf gene in amphioxus: Insights into the evolution of the TCF/LEF gene family during vertebrate evolution. Dev Dyn 235: 3396-3403.

LOWE CJ, TERASAKI M, WU M, FREEMAN RM JR., RUNFT L, KWAN K, HAIGO S, ARONOWICZJ, LANDER E, GRUBER C, SMITH M, KIRSCHNER M, GERHART $J$ (2006). Dorsoventral patterning in hemichordates: Insights into early chordate evolution. PLoS Biol 4: e291.

LU TM, LUO YJ, YU JK (2012). BMP and Delta/Notch signaling control the development of amphioxus epidermal sensory neurons: insights into the evolution of the peripheral sensory system. Development 139: 2020-2030.

MARLOW FL, MULLINS MC (2008). Bucky ball functions in Balbiani body assembly and animal-vegetal polarity in the oocyte and follicle cell layer in zebrafish. Dev Biol 321: 40-50

MARLOW H, TOSCHES MA, TOMER R, STEINMETZ PR, LAURI A, LARSSON T, ARENDT D (2014). Larval body patterning and apical organs are conserved in animal evolution. BMC Biol 12: 7. http://www.biomedcentral.com/1741-7007/12/7.

MARTINDALE MQ, ANDREAS HEJNOL A (2009). A developmental perspective: Changes in the position of the blastopore during bilaterian evolution. Dev Cell 17: $162-174$.

MARTINDALE MQ, HEJNOL A (2009). A developmental perspective: Changes in the position of the blastopore during bilaterian evolution. Dev Cell 17: 162-174.

MOLINA MD, DE CROZÉ N, HAILLOT E, LEPAGE T (2013). Nodal: master and commander of the dorsal-ventral and left-right axes in the sea urchin embryo. Cur Opin Gen Dev 23: 445-453.

MOROV AR, UKIZINTAMBARA T, SABIROV RM, YASUI K. (2016). Acquisition of the dorsal structures in chordate amphioxus. Open Biol. 6: 160062. (http://dx.doi. org/10.1098/rsob.160062).

NISHIDA H (2005). Specification of embryonic axis and mosaic development in ascidians. Dev Dyn 233:1177-1193.

ONAI T, YU JK, BLITZ IL, CHO KWY, HOLLAND LZ (2010). Opposing Nodal/Vg1 and BMP signals mediate axial patterning in embryos of the basal chordate amphioxus. Dev Biol 344: 377-389.

OWEN R (1866). On the Anatomy of Vertebrates. Vol. I. Fish and Reptiles. Longmans, Green, and Co., London.

PANOPOULOU GD, CLARK MD, HOLLAND LZ, LEHRACH H, HOLLAND ND (1998). AmphiBMP2/4, an amphioxus bone morphogenetic protein closely related to Drosophila decapentaplegic and vertebrate BMP2 and BMP4: Insights into evolution of dorsoventral axis specification. Dev Dyn 213:130-139.
PELEGRIF (2003). Maternal factors in zebrafish development. Dev Dyn228:535-554

PENG CJ, WIKRAMANAYAKE AH (2013). Differential regulation of Disheveled in a novel vegetal cortical domain in sea urchin eggs and embryos: Implications for the localized activation of canonical Wnt signaling. PLOS ONE 8: e80693.

PENNERSTORFER M, SCHOLTZ G (2012) Early cleavage in Phoronis muelleri (Phoronida) displays spiral features. Evol Dev 14: 484-500.

PLICKERT G, JACOBY V, FRANKU, MÜLLERWA, MOKADYO (2006). Wnt signaling in hydroid development: Formation of the primary body axis in embryogenesis and its subsequent patterning. Dev Biol 298: 368-378.

PUTNAM NH, SRIVASTAVAM, HELLSTEN U, DIRKS B, CHAPMAN J, SALAMOV A, TERRY A, SHAPIRO H, LINDQUIST E, KAPITONOV VV, JURKA J, GENIKHOVICH G, GRIGORIEV IV, LUCAS SM, STEELE RE, FINNERTY JR, TECHNAU U, MARTINDALEMQ, ROKHSARDS (2007). Sea anemone genome reveals ancestral eumetazoan gene repertoire and genomic organization. Science 317: 86-94.

RANGE RC, ANGERER RC, ANGERER LM (2013). Integration of canonical and noncanonical Wnt signaling pathways patterns the neuroectoderm along the anterior-posterior axis of sea urchin embryos. PLoS Biol 11: e1001467.

RANGE RC, WEI Z (2016). An anterior signaling center patterns and sizes the anterior neuroectoderm of the sea urchin embryo. Development 143: 1523-1533.

RANSICK A, DAVIDSON EH (1993). A complete second gut induced by transplanted micromeres in the sea urchin embryo. Science 259: 1134-1138.

RENTZSCH F, ANTON R, SAINA M, HAMMERSCHMIDT M, HOLSTEIN TW, TECHNAUU (2006). Asymmetric expression of the BMP antagonists chordinand gremlin in the sea anemone Nematostella vectensis: Implications for the evolution of axial patterning. Dev Biol 296: 375-387.

ROKAS A, KRÜGER D, CARROLL SB (2005). Animal evolution and the molecular signature of radiations compressed in time. Science 310: 1933-1938.

RÖTTINGERE, LOWE CJ (2012). Evolutionary crossroads in developmental biology: hemichordates. Development 139: 2463-2475.

SAIJOH Y, ADACHI H, SAKUMA R, YEO CY, YASHIRO K, WATANABE M, HASHIGUCHI H, MOCHIDA K, OHISHI S, KAWABATA M, MIYAZONO K, WHITMAN M, HAMADA H (2000). Left-right asymmetric expression of lefty2 and nodal is induced by a signaling pathway that includes the transcription factor FAST2. Mol Cell 5: 35-47.

SAINAM, GENIKHOVICHAG, RENFERAE, TECHNAUU (2009). BMPs and Chordin regulate patterning of the directive axis in a sea anemone. Proc Natl Acad Sci USA 106: 18592-18597.

SASAI Y, LU B, STEINBEISSER H, DE ROBERTIS EM (1995). Regulation of neura induction by the Chd and BMP-4 antagonistic patterning signals in Xenopus. Nature 376: 333-336.

SCHIER AF, SHEN MM (2000). Nodal signalling in vertebrate development. Nature 403: 385-389.

SCHLOSSER G (2005). Evolutionary origins of vertebrate placodes: Insightsfrom developmental studies and from comparisons with other deuterostomes. J Exp Zool B (Mol Dev Evol) 304B: 347-399.

SHIRAE-KURABAYASHI M, NISHIKATAT, TAKAMURAK, TANAKAKJ, NAKAMOTO C, NAKAMURAA (2006). Dynamic redistribution of vasa homolog and exclusion of somatic cell determinants during germ cell specification in Ciona intestinalis. Development 133: 2683-2693.

SHU DG, LUO HL, CONWAY MORRIS S, ZHANG XL, HU SX, CHEN L, HAN J, ZHU M, LI Y, CHEN LZ (1999). Lower Cambrian vertebrates from south China Nature 402: 42-46.

SINIGAGLIA C, BUSENGDAL H, LECLERE L, TECHNAU U, RENTZSCH F (2013). The bilaterian head patterning gene six $3 / 6$ controls aboral domain development in a cnidarian. PLoS Biol 11: e1001488.

SMITH AB, ZAMORA S, ÁLVARO JJ (2013). The oldest echinoderm faunas from Gondwana show that echinoderm body plan diversification was rapid. Nature Comms 4, 1385

SOUKUP V, HORÁCEK I, CERNY R (2013). Development and evolution of the vertebrate primary mouth. J Anat 222: 79-99.

STEPHEN Q. DORNBOS SQ, BOTTJER DJ (2001). Taphonomy and environmental distribution of helicoplacoid echinoderms. PALAIOS 16: 197-204

SCHWAIGER M, SCHÖNAUER A, RENDEIRO AF, PRIBITZER C, SCHAUER A GILLES AF, SCHINKO JB, RENFER E, FREDMAN D, TECHNAU U (2014). Evolutionaryconservation of the eumetazoan gene regulatory landscape. Genome 
Res 24, 639-650.

TAKADA N, GOTO T, SATOH N (2002). Expression pattern of the brachyury gene in the arrow worm Paraspadella gotoi (Chaetognatha). Genesis 32: 240-245.

TAKAMURAK, FUJIMURAM, YAMAGUCHIY (2002). Primordial germ cells originate from the endodermal strand cells in the ascidian Ciona intestinalis. Dev Genes Evol 212: 11-18.

TAO Q, YOKOTA C, PUCK H, KOFRON M, BIRSOY B, YAN D, ASASHIMAM, WYLIE CC, LINX, HEASMANJ (2005). Maternal Wnt11 activates the canonical Wnt signaling pathway required for axis formation in Xenopus embryos. Cell 120: 857-871.

VORONINA E, SEYDOUX G, SASSONE-CORSI P, NAGAMORI I (2011). RNA granules in germ cells. Cold Spring Harb Perspect Biol. 3:a002774 (doi: 10.1101/ cshperspect.a002774).

WANG J, LI G, QIAN GH, HUA JH, WANG YQ (2016). Expression analysis of eight amphioxus genes involved in the Wnt/ $\beta$-catenin signaling pathway. Zool Res 37: 136-143.

WATANABE H, HOANG VT, MÄTTNER R, HOLSTEIN TW (2009). Immortality and the base of multicellular life: lessons from cnidarian stem cells. Sem Cell Dev Biol 20: 1114-1125

WATANABE H, KUHNA, FUSHIKI M, AGATAK, O" ZBEK S, FUJISAWAT, HOLSTEIN TW (2014). Sequential actions of $\beta$-catenin and Bmp pattern the oral nerve net in Nematostella vectensis. Nature Comm 5:5536.

WEI Z, RANGE R, ANGERER R, ANGERER L (2012). Axial patterning interactions in the sea urchin embryo: suppression of nodal by Wnt1 signaling. Development 139: 1662-1669.

WEITZELHE, ILLIESMR, BYRUM CA, XURH, WIKRAMANAYAKEAH, ETTENSOHN CA (2004). Differential stability of $\beta$-catenin along the animal-vegetal axis of the sea urchin embryo mediated by disheveled. Development 131: 2947-2956.

WENNBERG SA, JANSSEN R, BUDD GE (2008). Early embryonic development of the priapulid worm Priapulus caudatus. Evol Dev 10: 326-338.

WIKRAMANAYAKE AH, PETERSON R, CHEN J, HUANG L, BINCE JM, MCCLAY DR, KLEIN WH (2004). Nuclear $\beta$-catenin-dependent Wnt8 signaling in vegetal cells of the early sea urchin embryo regulates gastrulation and differentiation of endoderm and mesodermal cell lineages. Genesis 39: 194-205.

WU HR, CHEN YT, SU YH., LUO YJ, HOLLAND LZ, YU JK (2011). Asymmetric localization of germline markers Vasa and Nanos during early development in the amphioxus Branchiostoma floridae. Dev Biol 353: 147-159.

YAGUCHIS, YAGUCHIJ, ANGERERRC, ANGERER LM (2008). AWnt-FoxQ2-nodal pathway links primary and secondary axis specification in sea urchin embryos.
Dev Cell 14: 97-107.

YAJIMA M, WESSEL GM (2012). Autonomy in specification of primordial germ cells and their passive translocation in the sea urchin. Development 139: 3786-3794.

YAKOVLEV KV (2016). Localization of germ plasm-related structures during sea oogenesis. Dev Dyn 245: 56-66.

YASUI K, LI G, WANG Y, SAIGA H, ZHANG P, AIZAWA S (2002). $\beta$-Catenin in early development of the lancelet embryo indicates specific determination of embryonic polarity. Dev Growth Differ 44: 467-475.

YASUI K, SAIGA H, WANG Y, ZHANG PJ, SEMBA I (2001). Early expressed genes showing a dichotomous developing pattern in the lancelet embryo. Dev Growth Differ 43: 185-194.

YASUI K, ZHANG SC, UEMURA M, SAIGA H (2000). Left-right asymmetric expression of BbPtx, a Ptx-related gene, in a lancelet species and the developmenta left-sidedness in deuterostomes. Development 127: 187-195.

YU JK, HOLLAND LZ, HOLLAND ND (2002). An amphioxus Nodal gene (AmphiNodal) with early symmetrical expression in the organizer and mesoderm and later asymmetrical expression associated with left-right axis formation. Evol Dev 4:418-425.

YU JK, HOLLAND ND, HOLLAND LZ (2003) AmphiFoxQ2, a novel winged helix forkhead gene, exclusively marks the anterior end of the amphioxus embryo. Dev Genes Evol 213:102-105.

YU JK, SATOU Y, HOLLAND ND, SHIN-I T, KOHARA Y, SATOH N, BRONNERFRASER M, HOLLAND LZ (2007). Axial patterning in cephalochordates and the evolution of the organizer. Nature 445: 613-617.

YUE JX, LIKL, YU JK (2015). Discovery of germline-related genes in Cephalochordate amphioxus: A genome wide survey using genome annotation and transcriptome data. Marine Genomics 24: 147-157.

YUE JX, YU JK, PUTNAM NH, HOLLAND LZ (2014). The transcriptome of an amphioxus, Asymmetron lucayanum, from the Bahamas: A window into chordate evolution. Genome Biol Evol 6: 2681-2696.

ZAMORA S, RAHMAN IA, SMITH AB (2012) Plated Cambrian bilaterians reveal the earliest stages of echinoderm evolution. PLOS ONE 7: e38296.

ZHANG J, HOUSTON DW, KING ML, PAYNE C, WYLIE C, HEASMAN J (1998). The role of maternal VegT in establishing the primary germ layers in Xenopus embryos. Cell 94: 515-524

ZHANG QJ, LUO YJ, WU HR, CHEN YT, YU JK (2013). Expression of germline markers in three species of amphioxus supports a preformation mechanism of germ cell development in cephalochordates. EvoDevo 4: 17. 


\section{Further Related Reading, published previously in the Int. J. Dev. Biol.}

Evolution, divergence and loss of the Nodal signalling pathway: new data and a synthesis across the Bilateria Cristina Grande, José María Martín-Durán, Nathan J. Kenny, Marta Truchado-García and Andreas Hejnol Int. J. Dev. Biol. (2014) 58: 521-532.

\section{Contemporary Spiralian Developmental Biology} Jonathan Henry

Int. J. Dev. Biol. (2014) 58: 385-387.

From the American to the European amphioxus: towards experimental Evo-Devo at the origin of chordates

Jordi Garcia-Fernàndez, Senda Jiménez-Delgado, Juan Pascual-Anaya, Ignacio Maeso, Manuel Irimia, Carolina Minguillón, Èlia Benito-Gutiérrez, Josep Gardenyes, Stéphanie Bertrand and Salvatore D'Aniello

Int. J. Dev. Biol. (2009) 53: 1359-1366

https://doi.org/10.1387/ijdb.072436jg

Peter Holland, homeobox genes and the developmental basis of animal diversity Sebastian M. Shimeld

Int. J. Dev. Biol. (2008) 52: 3-7

https://doi.org/10.1387/ijdb.072394ss

Who came first--larvae or adults? Origins of bilaterian metazoan larvae. Belinda J Sly, Margaret S Snoke and Rudolf A Raff Int. J. Dev. Biol. (2003) 47: 623-632.

The first bilaterian organisms: simple or complex? New molecular evidence J Baguna, I Ruiz-Trillo, J Paps, M Loukota, C Ribera, U Jondelius, M Riutort Int. J. Dev. Biol. (2001) 45: S133-S134.

5 yr ISI Impact Factor $(2013)=2.879$

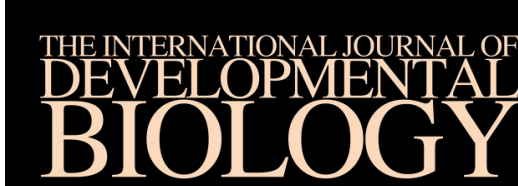

Volume 58 Nos. 6/7/8

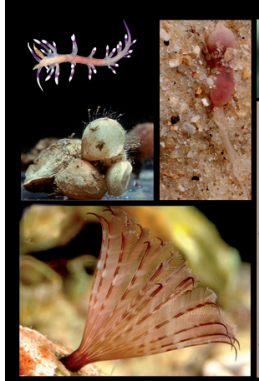

Spiralian Model Systems

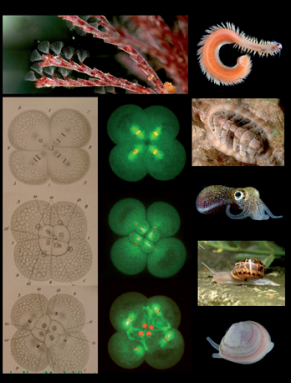

皮

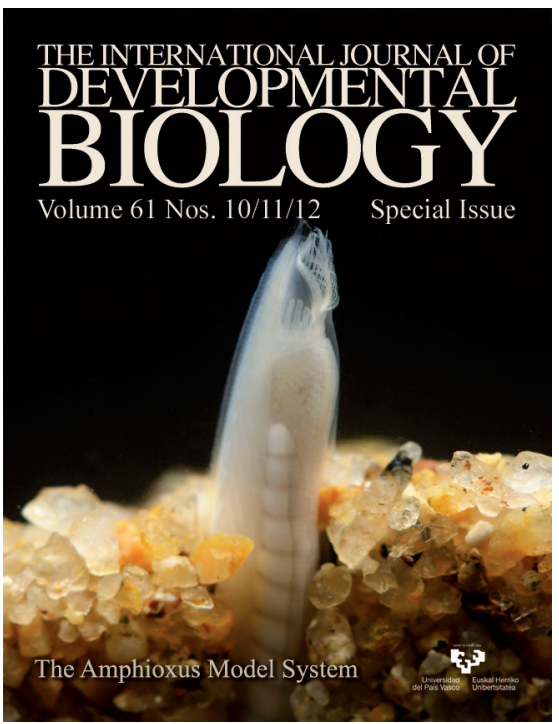

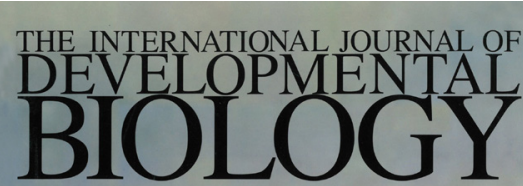

Volume 47 Nos. 7/8 Special Issue

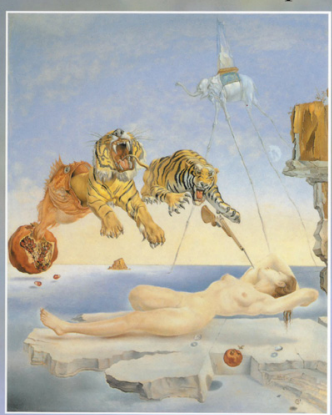

Evolution \& Development

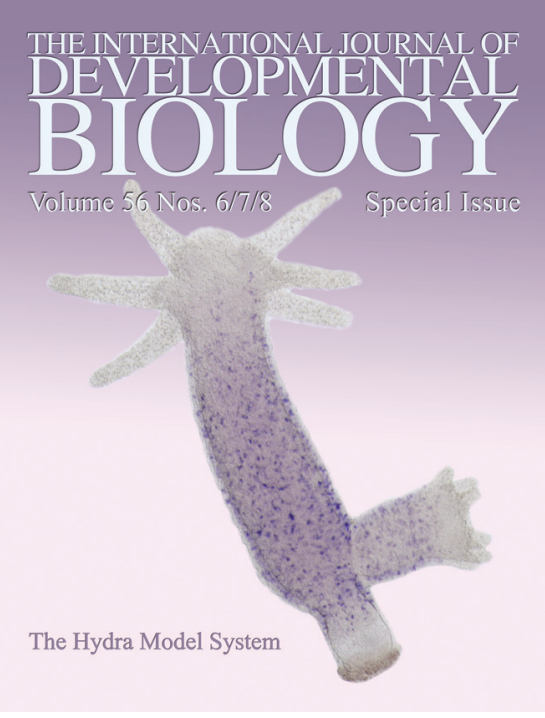

